\title{
Systemic markers of inflammation are independently associated with S100B concentration: results of an observational study in subjects with acute ischaemic stroke
}

\author{
Christopher Beer ${ }^{1,2,3,4^{*}}$, David Blacker ${ }^{2,5}$, Michael Bynevelt ${ }^{4,5}$, Graeme J Hankey ${ }^{2,4}$, lan B Puddey ${ }^{2,4}$
}

\begin{abstract}
Background: Vascular dysfunction and brain inflammation are thought to contribute to the pathophysiology of cerebral injury in acute stroke. However acute inflammation and vascular dysfunction may simply be markers of an acute phase response to cerebral injury, reflecting the size of the cerebral lesion. We aimed to determine if systemic markers of vascular dysfunction and inflammation are independently associated with concentrations of the astroglial protein S100B, a marker of brain injury, in participants with acute ischaemic stroke.

Methods: Fifty-seven men and women recruited within 96 hours of acute ischaemic stroke at two tertiary hospitals participated in this cross sectional observational study. Clinical, imaging (stroke lesions area measured with perfusion (T) and laboratory data were the independent variables and co-variates. The outcome variable was serum $\mathrm{S} 100 \mathrm{~B}$ concentration, analysed by multivariate regression.

Results: High sensitivity-CRP $(B=0.41)$ and lesion area $(B=0.69)$ were independently associated with S100B concentration $\left(R^{2}=0.75, p<0.01\right)$. Other variables with significant univariate associations with $S 100 B$ concentration were not independently associated with S100B concentration in the final multivariate model.
\end{abstract}

Conclusion: The degree of systemic inflammation is associated with S100B concentration in acute ischaemic stroke, independent of the size of the ischaemic lesion.

\section{Background}

Acute ischaemic stroke is associated with a rise in systemic markers of endothelial activation, inflammation and oxidative stress [1-6]. At the site of brain injury vascular dysfunction, oxidative stress and brain inflammation are thought to contribute to the pathophysiology of cerebral injury in acute stroke $[2,7]$. However, it is uncertain whether these factors simply represent an "acute phase" response to the cerebral injury, and associated complications such as immobility, or are important independent predictors of the degree of cerebral injury resulting from an acute ischaemic insult.

\footnotetext{
* Correspondence: christopher.beer@uwa.edu.au

'Western Australian Centre for Health and Ageing, University of Western Australia

Full list of author information is available at the end of the article
}

Much evidence shows that inflammation in the setting of acute ischaemic stroke is associated with infarct size, supporting the hypothesis that inflammation in acute stroke primarily reflects an acute phase response determined by the degree of cerebral injury $[1,8]$. However the magnitude of the acute phase response appears to also be independent an predictor of clinical outcome [9]. In patients with lacunar syndromes, who tend to have small volume lesions, progression of neurologic symptoms is associated with markers of the acute phase response [10]. These data suggest that inflammation may be an important independent factor in the pathophysiology of acute ischaemic stroke.

S100B is a peptide derived largely from astrocytes. In normal physiology S100B has multiple local regulatory effects on cell division and metabolism. Ischaemia is associated with raised S100B levels [11,12]. This is 
thought to be due to damage to astrocytes. Thus S100B concentrations are marker of the degree and severity of cellular injury in acute ischaemic stroke.

We conducted this study to test the hypothesis that endothelial function, inflammation and oxidative stress are independently associated with the degree of cellular injury in acute ischaemic stroke. We aimed to determine if endothelial function, inflammation and oxidative stress are associated with $\mathrm{S100B}$ concentration in acute ischaemic stroke, and in particular if any association is independent of infarct size.

\section{Methods}

\section{Design}

Cross-sectional observational study.

\section{Setting and participants}

Patients were recruited at two teaching hospitals in Perth, Western Australia between May 2005 and November 2008. Patients admitted with acute ischaemic stroke within 96 hours of onset were eligible to participate. Exclusion criteria were: blood glucose level $>13 \mathrm{mmol} / \mathrm{L}$; acute co-morbid condition; creatinine $>120 \mathrm{umol} / \mathrm{L}$; haemorrhage seen on initial CT; and history of sensitivity to contrast. Clinical records were reviewed subsequent to the patient's discharge to confirm a final clinical diagnosis of an acute cerebral ischaemic event and classify the clinical syndrome using the Oxfordshire Community Stroke Project classification [13].

\section{Assessments}

Clinical characteristics were assessed using the National Institutes of Health Stroke Scale (NIHSS), [14] Modified Barthel Index (MBI) [15] and Modified Rankin Scale (MRS) [16]. Laboratory data were collected to assess S100B concentrations [11], inflammation (C-reactive protein [CRP] and fibrinogen [9]), endothelial activation (E-selectin [1]), endothelial cell damage (Von Willebrand factor [vWF] [1]) and oxidative stress [F2-isoprostanes] [4]). With the exception of F2-isoprostanes, all assays were performed by the PathWest Laboratory Medicine Units at Royal Perth and Sir Charles Gairdner Hospitals, using routine collection and analysis procedures. For analysis of F2-isporostanes, $5 \mathrm{ml}$ of whole venous blood was collected into cold EDTA tubes containing reduced glutathione and centrifuged as soon as possible at 1000 $\mathrm{g}$ for $10 \mathrm{~min}$ at $4^{\circ} \mathrm{C}$. The plasma was protected from oxidation by the addition of butylated hydroxytoluene at a final concentration of $20 \mu \mathrm{g} / \mathrm{ml}$ plasma and stored at $-80^{\circ} \mathrm{C}$ until analysis by gas chromatography/mass spectrometry [17]. Blood pressure was assessed using validated ' $[18,19]$ oscillometric ambulatory blood pressure monitors (Oscar 2, SunTech Medical, Morrisville NC USA) worn by participants for 24 hours after enrolment.
Participants underwent perfusion CT scanning. Five patients were imaged prior to July 2005. A single $10 \mathrm{~mm}$ slice was taken at the level of the third ventricle. Cycle time was $1 \mathrm{~s}$. Subsequent to July 20058 slices were acquired on mulitdetector machines (Philips Brilliance 64 slice scanner). $40 \mathrm{~mL}$ of non-ionic contrast ('Optiray') was administered over 10 seconds using an intravenous cannula in the antecubital fossa. The multidetector machine protocol was: length $40 \mathrm{~mm}$, thickness $5 \mathrm{~mm}$, increment $0 \mathrm{~mm}, \mathrm{kV} \mathrm{120,} \mathrm{mAs} 100$, cycle time 1.5, cycles 45, Resolution High, Collimation $32 \times 1.25$, Rotation time $0.4 \mathrm{sec}$, Filter Smooth UA, matrix 512. Post processing and analysis was completed on Philips and GE workstations. When multiple slices were available, the slice with greatest lesion area evident on the plain CT was chosen for analysis. Infarct size was measured by an experienced neuroradiologist $(\mathrm{MB})$ blinded to treatment allocation.

\section{Data analysis}

SPSS for MS Windows was used to analyse data. Lognormal data were log transformed prior to analysis. Non-normal data were analysed using non parametric tests. Categorical variables were assessed with the chi squares or fisher exact test. Linear regression modeling was used to examine the association between predictor variables and concentration of S100B. Only non-missing data were included in the modeling exercise. This commenced with a series of univariate models to identify all candidate predictor variables. These significant variables were then included in a multivariate logistic regression model and removed using a backward stepwise process if their significance was not retained. Box-plots of the remaining variables were re-inspected to ensure that outlying values were not present, before producing the final parsimonious model.

\section{Ethical considerations}

The study was approved by the Royal Perth and Sir Charles Gairdner Hospitals Ethics Committees. Able participants provided written informed consent. If there was uncertainty regarding the person's ability to provide informed consent agreement to study participation was also sought from the person's next of kin. The procedures followed were in accordance with the Helsinki Declaration.

\section{Results}

\section{Cohort characteristics}

An heterogeneous group of 57 acute ischaemic stroke patients participated in the study (Table 1). The mean age of participants was 68 years. Participants were enrolled a mean of 53 hours after the onset of symptoms. Although there was wide variability in the sample, 
Table 1 Cohort characteristics

\begin{tabular}{|c|c|}
\hline Variable & Mean \pm SD or $n(\%)$ \\
\hline Age (years) & $67.8+13.7$ \\
\hline Male (\%) & $39(68 \%)$ \\
\hline Enrolled (hours) & $52.6 \pm 21.6$ \\
\hline Hypertension & $35(61 \%)$ \\
\hline Atrial fibrillation & $10(18 \%)$ \\
\hline Hypercholesterolaemia & $11(19 \%)$ \\
\hline Diabetes & $13(23 \%)$ \\
\hline Smoking & $21(37 \%)$ \\
\hline \multicolumn{2}{|l|}{ Aetiology } \\
\hline Large vessel & $6(11 \%)$ \\
\hline Small vessel & $8(14 \%)$ \\
\hline Cardioembolic & $24(42 \%)$ \\
\hline Other & $1(2 \%)$ \\
\hline Unknown & $18(32 \%)$ \\
\hline \multicolumn{2}{|l|}{ Syndrome } \\
\hline Total anterior circulation & $14(25 \%)$ \\
\hline Partial anterior circulation & $26(46 \%)$ \\
\hline Lacunar & $11(19 \%)$ \\
\hline Posterior circulation & $6(11 \%)$ \\
\hline Systolic blood pressure $(\mathrm{mmHg})$ & $142.1 \pm 19.3$ \\
\hline Diastolic blood pressure $(\mathrm{mmHg})$ & $80.2 \pm 11.2$ \\
\hline $\mathrm{NIH}$ stroke scale score & $8.5 \pm 7.8$ \\
\hline \multicolumn{2}{|l|}{ Modified Rankin scale score } \\
\hline $0-3$ & $17(30 \%)$ \\
\hline $4-5$ & $40(70 \%)$ \\
\hline Modified Barthel index score & $39.3 \pm 33.9$ \\
\hline Glucose (mmol/L) & $6.3 \pm 1.6$ \\
\hline Homocysteine (umol/L) & $9.9 \pm 3.8$ \\
\hline High sensitivity-CRP (mg/L) & $15.7 \pm 27.9$ \\
\hline Fibrinogen $(\mathrm{g} / \mathrm{L})$ & $4.2 \pm 1.2$ \\
\hline E-selectin (ng/mL) & $30.5 \pm 34.0$ \\
\hline von Willebrand Factor (\%) & $158.7 \pm 61.6$ \\
\hline S100B (ug/L) & $0.5 \pm 0.8$ \\
\hline F2-Isoprostanes (nmol/L) & $3.2 \pm 4.2$ \\
\hline Lesion area $\left(\mathrm{mm}^{2}\right)$ & $1001.9 \pm 1359.8$ \\
\hline
\end{tabular}

many participants had moderate - severe stroke (the mean NIH stroke scale score was $10,40 \%$ of participants had a modified Rankin score of 4 or 5 and the mean lesion area was $10 \mathrm{~cm}^{2}$ ).

\section{Factors associated with S100B concentrations}

Significant univariate associations were found between age, stroke syndrome, neurologic impairment (NIHSS Score), disability (Modified Barthel Index score), lesion area, hs-CRP and serum concentration of S100B. These are shown in Table 2. However, of these factors, only hs-CRP $(B=0.41)$ and lesion area $(B=0.69)$ remained
Table 2 Univariate and multivariate relationships (S100B as dependent variable) analysed by linear regression

\begin{tabular}{lcccc}
\hline Predictor & $\mathbf{B}$ & SE B & $\boldsymbol{B}$ & $\mathbf{p}$ \\
\hline Univariate Relationships & & & & \\
\hline Age & 0.01 & 0.01 & 0.27 & 0.05 \\
\hline Gender & -0.10 & 0.18 & -0.07 & 0.60 \\
\hline Hours to enrolment & 0.00 & 0.00 & 0.07 & 0.62 \\
\hline Hypertension & -0.06 & 0.17 & -0.05 & 0.73 \\
\hline Atrial fibrillation & 0.19 & 0.22 & 0.12 & 0.40 \\
\hline Hypercholesterolaemia & -0.20 & 0.22 & -0.12 & 0.37 \\
\hline Diabetes & 0.02 & 0.20 & 0.02 & 0.90 \\
\hline Smoking history & -0.09 & 0.17 & -0.07 & 0.60 \\
\hline Aetiology & -0.03 & 0.06 & -0.06 & 0.66 \\
\hline Clinical syndrome & -0.43 & 0.08 & -0.61 & 0.00 \\
\hline Systolic blood pressure & 0.00 & 0.00 & 0.00 & 0.99 \\
\hline Diastolic blood pressure & 0.00 & 0.01 & -0.07 & 0.58 \\
\hline NIHSS score & 0.56 & 0.20 & 0.36 & 0.01 \\
\hline Modified Rankin & 0.00 & 0.00 & 1.10 & 0.28 \\
\hline Modified Barthel & -0.01 & 0.00 & -0.36 & 0.01 \\
\hline Glucose & 1.52 & 0.84 & 0.25 & 0.08 \\
\hline Homocysteine & 0.01 & 0.52 & 0.00 & 0.99 \\
\hline Hs-CRP & 0.56 & 0.12 & 0.55 & 0.00 \\
\hline Fibrinogen & 0.10 & 0.07 & 0.20 & 0.16 \\
\hline E-Selectin & -0.09 & 0.29 & -0.04 & 0.75 \\
\hline von Willebrand factor activity & 0.00 & 0.00 & 2.26 & 0.03 \\
\hline F2-Isoprostanes & 0.04 & 0.31 & 0.02 & 0.89 \\
\hline Lesion area & 0.73 & 0.08 & 0.77 & 0.00 \\
\hline Final multivariate model & & & & \\
\hline Hs-CRP & 0.42 & 0.07 & 0.41 & 0.00 \\
\hline Lesion area & 0.65 & 0.07 & 0.69 & 0.00 \\
\hline & & & & \\
\hline
\end{tabular}

independently associated with S100B concentration in the final parsimonious multivariate model. Results of this model are also listed in Table 2. The multivariate model, including 54 participants with no missing data, showed that hs-CRP and lesion area explained the majority of variance in S100B (Adjusted $R^{2}=0.76, p<0.01$ ).

\section{Discussion}

\section{Main findings}

These data show that the relationship between S100B concentration and inflammation in participants with acute ischaemic stroke is independent of infarct size. These data establish an independent association between markers of inflammation and glial injury, suggesting that the inflammatory response to acute ischaemic injury may be a therapeutic target. The concept that limiting inflammation may limit brain injury is supported by evidence that components of the acute phase response to cerebral injury are deleterious. For example, CRP is 
known to inhibit generation of endothelial progenitor cells, which are necessary for angiogensis [20]. Future intervention studies are required to determine whether modifying the inflammatory response may limit cellular injury in acute ischaemic stroke.

\section{Results in context of other studies}

S100B has previously been found to be correlated with CRP in subjects with acute ischaemic stoke at 12, 24 and 72 hours after stroke, after controlling for gender, age and leukocyte count [21]. The present results extend those findings to show that the association between CRP and $\mathrm{S} 100 \mathrm{~B}$ is also independent of infarct size and a range of other potentially confounding variables.

Since our study was planned there has been an accumulation of data regarding the potential importance of inflammation and S100B concentrations in subjects with acute ischaemic stroke and other neurologic disorders. Both CRP concentrations at 72 hours, and S100B concentrations at twelve hours, have been found to be independently associated with clinical outcome following acute ischaemic stroke [22]. At nano-molar levels S100B has trophic effects which may an adaptive response to brain injury. However S100B at micromolar concentrations, may itself have neurotoxic (apoptotic) effects [23]. Over-expression of S100B has now been documented in a range of brain diseases [23]. Thus, although we were interested in S100B as a surrogate marker of clinical outcome, the higher concentrations of S100B may potentially cause, rather than simply reflecting, the degree of brain injury.

S100B also has pro-inflammatory effects. Although S100B is thought to be brain-specific, raised concentrations of S100B have been observed in systemic diseases without apparent neurologic involvement. Among subjects with systemic lupus erythematosus, concentrations of S100B were elevated (relative to controls) among subjects without central nervous system involvement, although to a lesser extent than among subjects with neurologic or psychiatric manifestations [24]. This could be because S100B is a sensitive marker of sub-clinical neurologic disease. It has since been postulated that S100B may act as an inflammatory mediator in subjects with non-neurologic disease. However S100B was found not to be associated with CRP in renal transplant recipients [25].

\section{Strengths of our study}

Ours is one of few studies to simultaneously assess infarct size, clinical variables and systemic markers of inflammation, oxidative stress and vascular function. We used a conservative approach in the modeling exercise. We included both sensitive clinical scales and imaging measures. For example, the NIHSS correlates with infarct volume $(r=0.68)$ and is a strong predictor of outcome after stroke [26,27]. Thus substantial residual confounding of the observed association between inflammation and S100B concentrations by lesion severity seems unlikely. We also accounted for the heterogeneity of acute ischaemic stroke syndromes by assessing stroke aetiology and clinical sub-type.

\section{Limitations}

There are several limitations to the study. We did not assess for other potential causes of inflammation (such as deep venous thrombosis and pulmonary atelectasis) which may confound the association between neurologic lesions and inflammation. Other potential confounding variables which were not controlled for include the degree of leukoariosis, and medical therapies. Determining lesion volume (rather than lesion size in one plane) would also have allowed greater confidence that differences due to lesion severity were adequately controlled in the multivariate models.

Interpretation of our results is also limited as $\mathrm{S} 100 \mathrm{~B}$ was only measured once. We were thus unable to account for differences in inflammatory status prior to the acute stroke event. The cross sectional design prevents any causal inferences being made. In addition, elevated S100B concentrations are not specific to ischaemic brain injury and the pattern of change in S100B levels is variable depending on the stroke subtype. Overall, serum S100B levels peak 2-3 days after an ischaemic stroke [12]. However in large middle cerebral artery (MCA) territory strokes serum S100B levels may not peak until 7 days [11]. Despite this variability, single S100B concentrations measured 2-3 days after non-lacunar ischaemic stroke were found to provide optimal predictive value compared to more complex measures [28]. Although S100B consistently appears to predict outcomes, data from subjects with traumatic brain injury indicate that the relationship between inflammation and alternative markers of brain injury (such as neuron specific enolase) may also warrant examination in subjects with acute ischaemic stroke [29].

\section{Conclusion}

The degree of systemic inflammation is independently associated with S100B concentrations in subjects with acute ischaemic stroke.

\section{Acknowledgements}

Funding from the NH\&MRC Centre of Clinical Research Excellence - Centre for Training in Clinical Cerebrovascular and Cardiovascular Research is acknowledged. The authors thank Melanie Rosenberg for her assistance with CT scan acquisition. A UWA Research Grant funded S100B assays. A UWA Small Bequest Research Grant funded isoprostane and CRP assays. 'Oscar 2' ambulatory blood pressure monitors were donated by SunTech Medical. Funding sources and donors had no role in the design or conduct of the study. The authors declare that they have no conflicts of interest or disclosures relevant to this work. 


\section{Author details}

'Western Australian Centre for Health and Ageing, University of Western Australia. ${ }^{2}$ School of Medicine and Pharmacology, University of Western Australia. ${ }^{3}$ Centre for Medical Research, Western Australian Institute for Medical Research. ${ }^{4}$ Royal Perth Hospital, Perth, Western Australia. ${ }^{5}$ Sir Charles Gairdner Hospital, Perth, Western Australia.

\section{Authors' contributions}

CB designed the study, carried out or supervised subject recruitment and collection of data, analysed the data and wrote the manuscript. DB assisted recruitment and data collection at the Sir Charles Gairdner site and assisted data interpretation and manuscript revision. MB analysed perfusion $\mathrm{CT}$ scans and assisted data interpretation and chapter revision. IBP and GH assisted in study design, data interpretation and manuscript revision. All authors have read and approved the final version of the manuscript.

\section{Competing interests}

The authors declare that they have no competing interests.

Received: 10 August 2010 Accepted: 29 October 2010

Published: 29 October 2010

\section{References}

1. Cherian P, Hankey GJ, Eikelboom JW, Thom J, Baker Rl, McQuillan A, Staton J, Yi Q: Endothelial and platelet activation in acute ischemic stroke and its etiological subtypes. Stroke 2003, 34:2132-2137.

2. Dirnagl U, ladecola C, Moskowitz MA: Pathobiology of ischaemic stroke: an integrated view. Trends Neurosci 1999, 22:391-397.

3. Lip GYH, Blann AD, Farooqi IS, Zarifis J, Sagar G, Beevers DG: Sequential alterations in haemorheology, endothelial dysfunction, platelet activation and thrombogenesis in relation to prognosis following acute stroke: The West Birmingham Stroke Project. Blood Coagulation \& Fibrinolysis 2002, 13:339-347.

4. Sanchez-Moreno C, Dashe JF, Scott T, Thaler D, Folstein MF, Martin A: Decreased Levels of Plasma Vitamin C and Increased Concentrations of Inflammatory and Oxidative Stress Markers After Stroke. Stroke 2004, 35:163-168.

5. van Kooten F, Ciabattoni G, Patrono C, Dippel DWJ, Koudstaal PJ: Platelet Activation and Lipid Peroxidation in Patients With Acute Ischemic Stroke. Stroke 1997, 28:1557-1563.

6. Smith CJ, Emsley HC, Gavin CM, Georgiou RF, Vail A, Barberan EM, del Zoppo GJ, Hallenbeck JM, Rothwell NJ, Hopkins SJ, Tyrrell PJ: Peak plasma interleukin- 6 and other peripheral markers of inflammation in the first week of ischaemic stroke correlate with brain infarct volume, stroke severity and long-term outcome. BMC Neurol 2004, 4:2.

7. Kelly PJ, Morrow JD, Ning M, Koroshetz W, Lo EH, Terry E, Milne GL, Hubbard J, Lee H, Stevenson E, et al: Oxidative Stress and Matrix Metalloproteinase-9 in Acute Ischemic Stroke: The Biomarker Evaluation for Antioxidant Therapies in Stroke (BEAT-Stroke) Study. Stroke 2008, 39:100-104.

8. Eikelboom JW, Hankey GJ, Baker Rl, McQuillan A, Thom J, Staton J, Cole V, Yi Q: C-reactive protein in ischemic stroke and its etiologic subtypes. Journal of Stroke and Cerebrovascular Diseases 2003, 12:74-81.

9. Muir KW, Weir CJ, Alwan W, Squire IB, Lees KR: C-Reactive Protein and Outcome After Ischemic Stroke. Stroke 1999, 30:981-985.

10. Audebert HJ, Pellkofer TS, Wimmer ML, Haberl RL: Progression in lacunar stroke is related to elevated acute phase parameters. Eur Neurol 2004, 51:125-131.

11. Herrmann M, Ehrenreich $\mathrm{H}$ : Brain derived proteins as markers of acute stroke: their relation to pathophysiology, outcome prediction and neuroprotective drug monitoring. Restor Neurol Neurosci 2003, 21:177-190.

12. Rothermundt $\mathrm{M}$, Peters $\mathrm{M}$, Prehn JH, Arolt V: S100B in brain damage and neurodegeneration. Microsc Res Tech 2003, 60:614-632.

13. Bamford J, Sandercock P, Dennis M, Burn J, Warlow C: Classification and natural history of clinically identifiable subtypes of cerebral infarction. Lancet 1991, 337:1521-1526.

14. Brott T, Adams HP Jr, Olinger CP, Marler JR, Barsan WG, Biller J, Spilker J, Holleran R, Eberle R, Hertzberg V, et al: Measurements of acute cerebral infarction: a clinical examination scale. Stroke 1989, 20:864-870.

15. Shah S, Vanclay F, Cooper B: Improving the sensitivity of the Barthel Index for stroke rehabilitation. J Clin Epidemiol 1989, 42:703-709.
16. Bamford JM, Sandercock PA, Warlow CP, Slattery J: Interobserver agreement for the assessment of handicap in stroke patients. Stroke 1989, 20:828.

17. Mori TA, Croft KD, Puddey IB, Beilin LJ: An improved method for the measurement of urinary and plasma F2-isoprostanes using gas chromatography-mass spectrometry. Anal Biochem 1999, 268:117-125.

18. Jones SC, Bilous M, Winship S, Finn P, Goodwin J: Validation of the OSCAR 2 oscillometric 24-hour ambulatory blood pressure monitor according to the International Protocol for the validation of blood pressure measuring devices. Blood Press Monit 2004, 9:219-223.

19. Goodwin J, Bilous M, Winship S, Finn P, Jones SC: Validation of the Oscar 2 oscillometric 24-h ambulatory blood pressure monitor according to the British Hypertension Society protocol. Blood Press Monit 2007, 12:113-117.

20. Verma S, Kuliszewski MA, Li SH, Szmitko PE, Zucco L, Wang CH, Badiwala MV, Mickle DA, Weisel RD, Fedak PW, et al: C-reactive protein attenuates endothelial progenitor cell survival, differentiation, and function: further evidence of a mechanistic link between C-reactive protein and cardiovascular disease. Circulation 2004, 109:2058-2067.

21. Worthmann H, Tryc AB, Goldbecker A, Ma YT, Tountopoulou A, Hahn A, Dengler $R$, Lichtinghagen $R$, Weissenborn $K$ : The temporal profile of inflammatory markers and mediators in blood after acute ischemic stroke differs depending on stroke outcome. Cerebrovasc Dis 2010, 30:85-92.

22. Sienkiewicz-Jarosz H, Galecka-Wolska M, Bidzinski A, Turzynska D, Sobolewska A, Lipska B, Plaznik A, Ryglewicz D: Predictive value of selected biochemical markers of brain damage for functional outcome in ischaemic stroke patients. Neurol Neurochir Pol 2009, 43:126-133.

23. Sen J, Belli A: S100B in neuropathologic states: the CRP of the brain? J Neurosci Res 2007, 85:1373-1380.

24. Portela LV, Brenol JC, Walz R, Bianchin M, Tort AB, Canabarro UP, Beheregaray S, Marasca JA, Xavier RM, Neto EC, et al: Serum S100B levels in patients with lupus erythematosus: preliminary observation. Clin Diagn Lab Immunol 2002, 9:164-166.

25. Gross S, Homan van der Heide JJ, van Son WJ, Gans RO, Foell D, Navis G, Bakker SJ: Body mass index and creatinine clearance are associated with steady-state serum concentrations of the cell damage marker S100B in renal transplant recipients. Med Sci Monit 2010, 16:CR318-324.

26. Johnston KC, Wagner DP, Haley EC Jr, Connors AF Jr: Combined clinical and imaging information as an early stroke outcome measure. Stroke 2002, 33:466-472.

27. Adams HP Jr, Davis PH, Leira EC, Chang KC, Bendixen BH, Clarke WR, Woolson RF, Hansen MD: Baseline NIH Stroke Scale score strongly predicts outcome after stroke: A report of the Trial of Org 10172 in Acute Stroke Treatment (TOAST). Neurology 1999, 53:126-131.

28. Foerch C, Singer OC, Neumann-Haefelin T, du Mesnil de Rochemont R, Steinmetz H, Sitzer M: Evaluation of serum S100B as a surrogate marker for long-term outcome and infarct volume in acute middle cerebral artery infarction. Arch Neurol 2005, 62:1130-1134.

29. Pleines UE, Morganti-Kossmann MC, Rancan M, Joller H, Trentz O, Kossmann T: S-100 beta reflects the extent of injury and outcome, whereas neuronal specific enolase is a better indicator of neuroinflammation in patients with severe traumatic brain injury. $J$ Neurotrauma 2001, 18:491-498.

doi:10.1186/1742-2094-7-71

Cite this article as: Beer et al: Systemic markers of inflammation are independently associated with S100B concentration: results of an observational study in subjects with acute ischaemic stroke. Journal of Neuroinflammation 2010 7:71. 